\title{
NeuroRehab \\ News \\ Ejercicio para la prevención de recaídas de dolor lumbar
}

Patología y Ejercicio

\section{Infografía}

\section{EJERCICIO PARA PREVENIR LAS RECAIDAS DEL DOLOR LUMBAR}

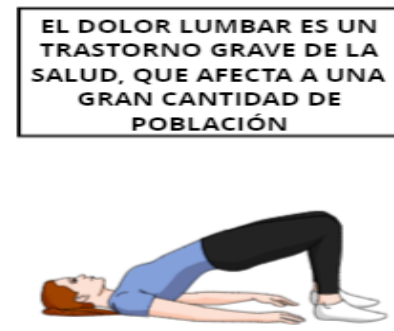

EXISTEN ESTUDIOS QUE

AFIRMAN QUE EL EJERCICIO

POST-TRATAMIENTO PUEDE

PREVENIR LA RECURRENCIA EN

EL DOLOR DE ESPALDA

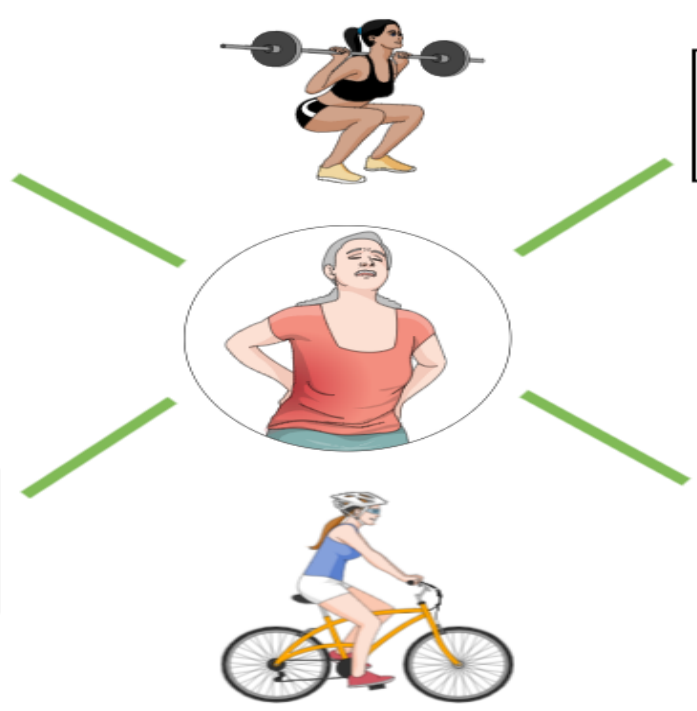

SE HA ENCONTRADO QUE MANTENERSE ACTIVO ES MÁS

MICAZ QUE DESCANSAR EN LA

CAMA, PARA TRATAR EL
DOLOR AGUDO DE ESPALDA

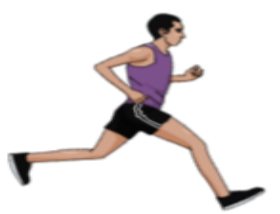

CUALQUIER EJERCICO, COMO EL FORTALECIMIENTO, EL EJERCICIO DE RESISTENCIAY EDUCACIÓN POSTURAL PUEDEN SER ADECUADOS PARA EVITAR RECAIDAS

El dolor lumbar es un problema clínico con una alta tasa de afectados. Los costes para el tratamiento de esta patología son muy altos. Es una de las principales causas por la que la población afectada no acude a sus puestos de trabajo. Una de las características del dolor lumbar es su tendencia a la reaparición.

La efectividad de los tratamientos para el dolor lumbar agudo ha sido ampliamente estudiada. Se ha comprobado que mantenerse activo es una buena opción para afrontar este problema clínico. Algunas investigaciones han encontrado que el ejercicio terapéutico ha resultado ser más efectivo que no realizar tratamiento $u$ otros tratamientos conservadores para reducir el dolor y mejorar la función en los pacientes con dolor lumbar crónico. Parece que continuar con el ejercicio tras el dolor lumbar puede ayudar a prevenir un nuevo episodio doloroso. 


\section{Sobre este artículo:}

\section{cc}

Fuente /s:

-Choi, B. K., Verbeek, J. H., Tam, W. W. S., Jiang, J. Y. (2010). Exercises for prevention of recurrences of low-back pain. Cochrane Database Systematic Review, 20;(1):CD006555

Fuente de la Imagen: imagen de NeuroRehabnews.com con fines unicamente ilustrativos.

Para citar este artículo: Carrasco-González E. Ejercicio para la prevención de recaídas de dolor lumbar. NeuroRehab News 2020 mar; 4(1):e0074.

Enrique

Carrasco González 